\title{
4-Hydroxypanduratin A: Potential Natural Compound against Dengue NSP1
}

\author{
Heenu Dhar and Poonam Salwan
}

Shree Guru Gobind Singh Tricentary University, Gurugram, Haryana, India

Corresponding author email: heenu_fmhs@sgtuniversity.org

\section{ABSTRACT}

Viral diseases are becoming deadlier day by day, Dengue is one the major re-emerging disease which affects not only rural but it affects a large population in urban areas too. This disease not only pose a threat to the developing countries, but also affects a large amount of people worldwide. This disease has become a major priority for the world health organisation. Every year a large amount of humans die due to unavailability of proper vaccine against this disease. Natural products have always played an important role in treating various viral and bacterial disease. Phyto-compounds are an approach to cure this disease and can help further to develop a vaccine against it. One of them is found in Boesenbergia Rotunda commonly known as Chinese ginger. One of major constituents of Chinese ginger is 4-hydroxypanduratin A. 4-hydroxypanduratin A has been used as neuro-protective, strong antioxidant, antibacterial and antifungal. In this research, in-silico studies has been performed to check whether 4-hydroxypanduratin A is a compound of interest or not.

KEY WORDS: 4-HYDROXYPANDURATINA,AUTODOCK, ATOMIC CONTACT ENERGY,BOESENBERGIAROTUNDA, DENGUE VIRUS (DENV).

\section{INTRODUCTION}

Dengue is an infection which is very common and increasing with a rapid rate. It is transmitted to humans by Aedesmosquito and is deadly in severe cases. Mortality rate when detected earlier and with the proper medical facilities is $1 \%$ but if this infection is left untreated it increases to as high as $20 \%$ and more. Last year 4.2 Million people were diagnosed with it, death rate also on an increase, 960 people in 2000 to 4032 in 2015 (World Health Organization (WHO) et. al. (2020).

Dengue Virus: Dengue virus (DENV) is of $11 \mathrm{~kb}$ and has a positive strand RNA which is enveloped and this virus belongs to the family of Flavivirus. DENV genome encodes for three structural proteins named as Capsid (C) Pre-membrane (prM) and envelope (E), these structural

Biosc Biotech Res Comm P-ISSN: 0974-6455 E-ISSN: 2321-4007

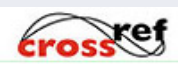

Identifiers and Pagination

Year: 2021 Vol: 14 No (6) Special Issue

Pages: $312-316$

This is an open access article under Creative

Commons License Attribn 4.0 Intl (CC-BY). DOI: http://dx.doi.org/10.21786/bbrc/14.7.67 proteins form the virus particle apart from that it have seven Non-structural proteins (NS) named as NS1, NS2A/B, NS3, NS4A/B and NS5. NS1 is involved in the viral RNA replication, NSA2 is responsible for interferon signalling and NS2B is cofactor for NS3, NS3 is responsible for protease and helicase activity, NS4A induces membrane rearrangements and NS4B is also responsible for interferon signalling lastly NS5 is responsible for the proper functioning of RNA polymerase and methyltransferase(M. G. Guzman (2010), F. Kato (2016).

The function of NSP1 is not yet fully discovered, researches are still going on but some studies suggest that NS1 is involved in the viral RNA replication and can be a target for a better therapeutic to achieve the vaccine against DENV(J. H. Amorim et. al. (2014)).

Natural Products: People are dying more frequently because of no proper medicine and treatment available to this infection.Phytocompounds are the option that always benefited humans, one of them is found in Boesenbergia Rotunda commonly known as Chinese ginger. One of major constituents of Chinese ginger is 4-hydroxypanduratin A. 4-hydroxypanduratin A has been used as neuroprotective, strong antioxidant, antibacterial and antifungal. 4-hydroxypanduratin A has been studied on various viral

\section{Article Information}

Received: $19^{\text {th }}$ May 2021 ccepted after revision: $29^{\text {th }}$ July 2021 
diseases and have shown positive response. This phytocompound is a hope to target the Dengue NS1Figure 1(P. Tuchinda (2002), L. J. Jing (2010)).

Figure 1: Inhibition of DENV. Figure represents that 4-hydroxypanduratin A inhibits dengue Virus

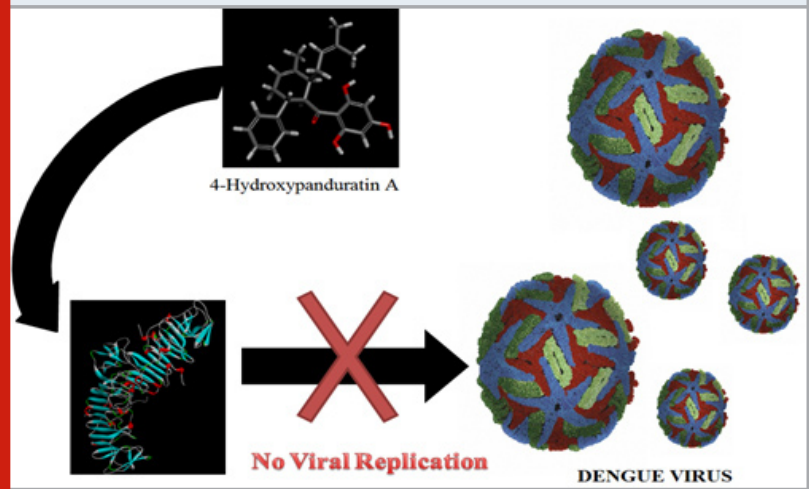

A research was conducted to analyse the effect of phytocompounds on viral fever, more specifically dengue. Binding energy of know nphyto-compounds, i.e.4hydroxypanduratin $\mathrm{A}$ and panduratin $\mathrm{A}$ with viral specific proteins i.e. NS2B and NS3 was determined by performing a docking analysis. Results were concluded on the basis of bindingenergy of the phyto-compounds and viral specific protein at different positions, wherein it was concluded that the aforementioned phyto-compounds were promising inhibitor ofNS2B and NS3. Moreover, some toxicity issues were also stated(N. Frimayanti (2011)). Another research was conducted to analyse the effect of 4-hydoxypanduratin A towards Japanese Encephalitits Virus (JEV) NS2B/NS3. Results were analysed on the basis of ADME properties and Binding energies of compound against JEV NS2/NS3 and it was concluded that 4-hydoxypanduratin Ainhibits the protease activity and it can be a promising drug against JEV infections(C. Seniya et. al. (2013).

Another research was conducted to study the effects of4hydroxypanduratin and on different bacterial strains i.e., Bacillus cereus, Bacillus subtilis, Staphylococcus aureus, and Proteus mirabilis. Results of in-vitro experiments revealed that 4-hydoxypanduratin A was rapidly killing the bacteria and have a very effective anti-bacterial activity against these four pathogens(S. D. Marliyana et. al. (2017). Another in-vitro research conducted to study the effects of Boesenbergia rotunda ethanol extract on Dengue Virus Type-2. Results were promising at the maximum dose and further research is still going on to target the specific Viral Proteins(M. Muhamadl et. al. (2007).

Research Questions: What is the effects of naturally occurring4-hydoxypanduratin A against DENV Viral protein NS1?

\section{METHODOLOGY}

Design: As Shown in Figure 2, PDB formatted files of 3D structure of 4-hydoxypanduratin A was downloaded from PubChem and 3D tertiary structure of DENV NS1 was downloaded from RCSB PDB. After downloading these files are formatted to a same file format as .pdb and then these two files are used for docking. Within the AutoDock software there are series of steps where .pdbqt, .glg, .dlg files are formed. .dlg file type is the docked file which can be visualised only in selected tools like AutoDock, Discovery Studio and PyMol. In this research .dlg file was visualised in Drug Discovery Studio and docked model least global energy and ACE was analysed.

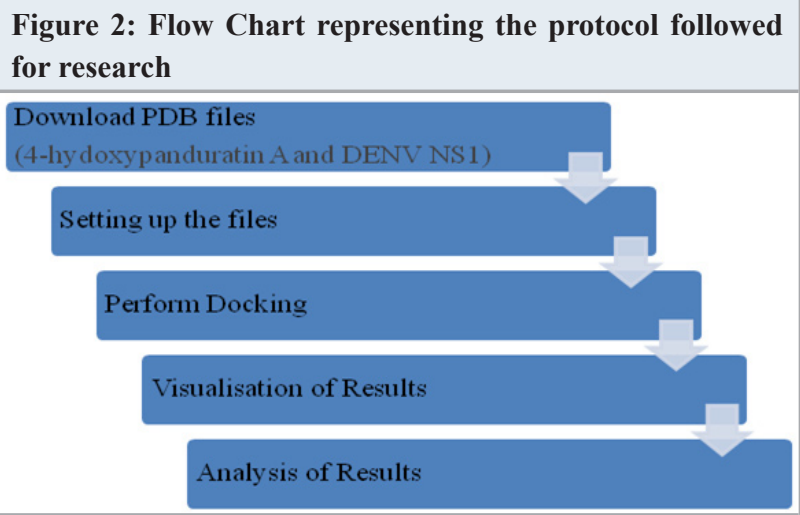

Figure 3: 3D Structure of Dengue Virus Non-Structural Protein NS1

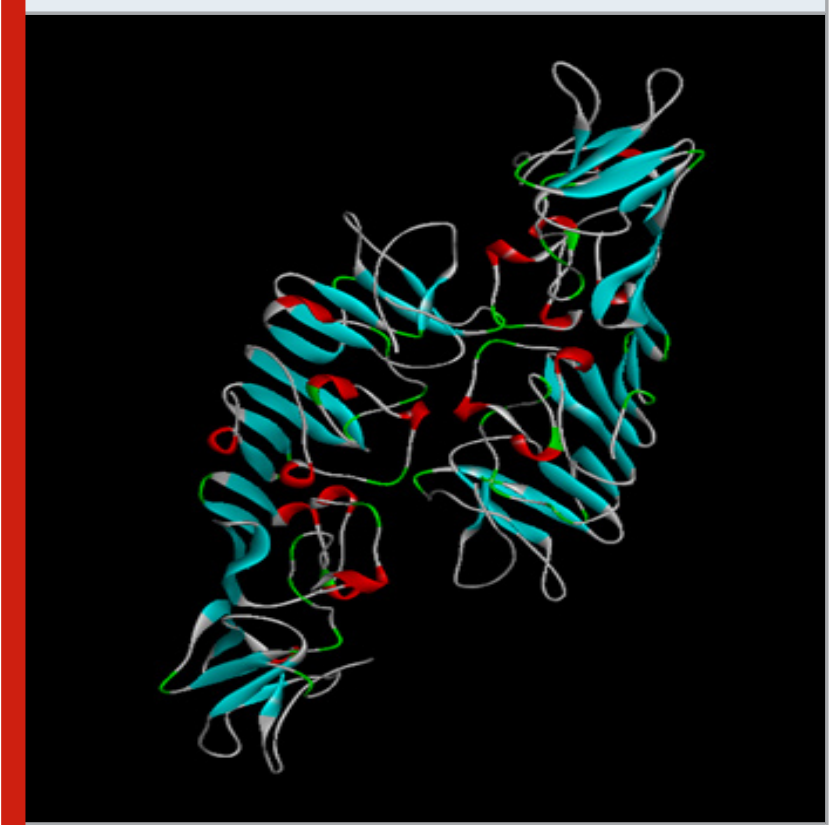

Sample: 3D structure of DENV NS1 was downloaded in the PDB format from an online server RCSB PDB and 3D structure for 4-hydoxypanduratin A was downloaded from PubChem in SDF format which is further converted to PDB format. These files were visualised in BOVIA Drug Discovery studio, Figure 3 is representing the DENV NS1 and Figure 4 is representing the 4-hydoxypanduratin A. These structure were further used to carry out docking and study the interaction between the ligand and the receptor.

\section{Instrument}

PubChem: SDF format file was downloaded for 3D 
structure of 4-hydroxypanduratin A from Public Chemistry (PubChem) (Figure 3). It is the largest collection of chemical information globally which can be accessed from anywhere in the world. Information regarding the chemical properties or $3 \mathrm{D}$ structure of different chemical compounds can be found here and in different file formats. This information is freely accessible and freely downloadable.

Figure 4: 3D Structure of 4-hydroxypanduratin A

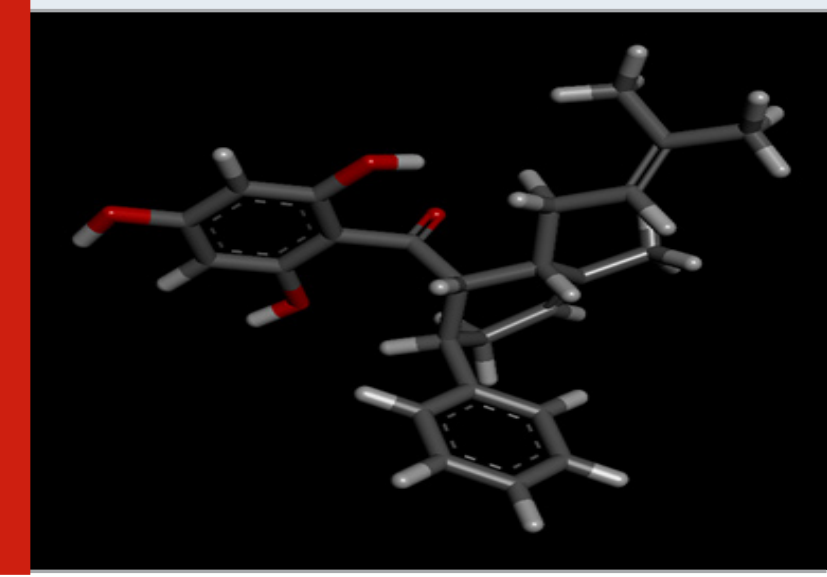

Figure 5: Docking Structure obtained

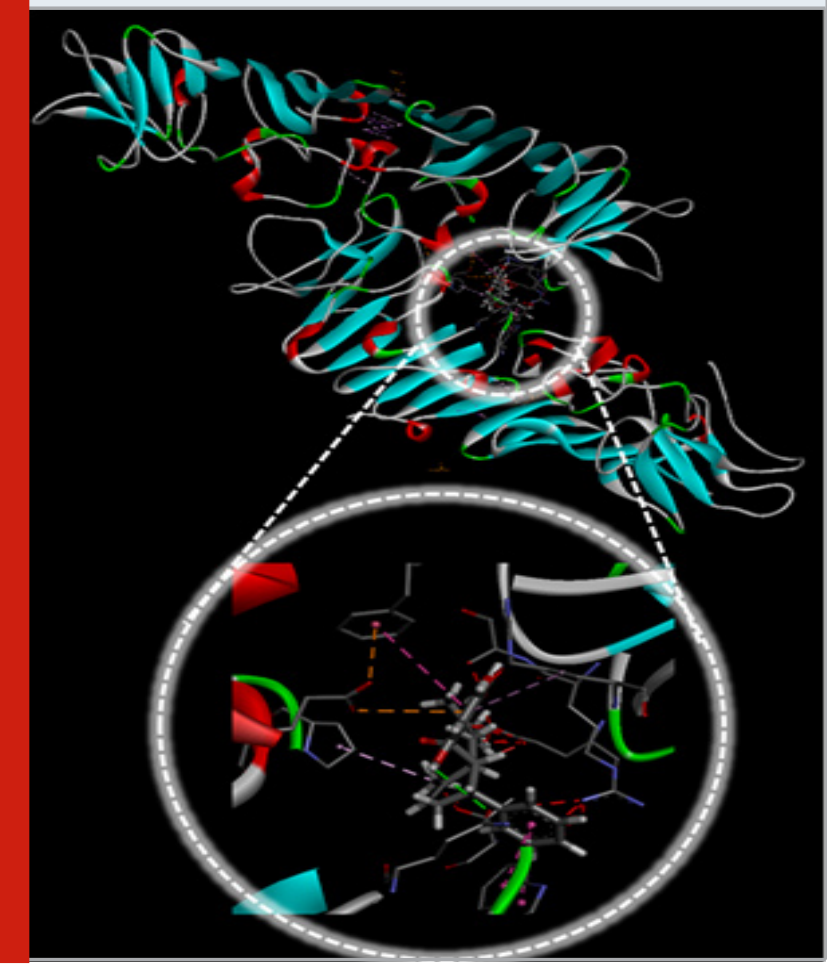

RCSB PDB: PDB format of DENV NS1 from Research Collaborator for Structural Bioinformatics. Protein Data Bank(RCSB PDB) was downloaded (Figure 4). It is a database to access the three dimensional structures of biological molecules that are large in size like proteins, nucleic acids etc. This information is freely available and can be downloaded from anywhere in the world.
Figure 6: 3D Docking Structure showing Amino Acids

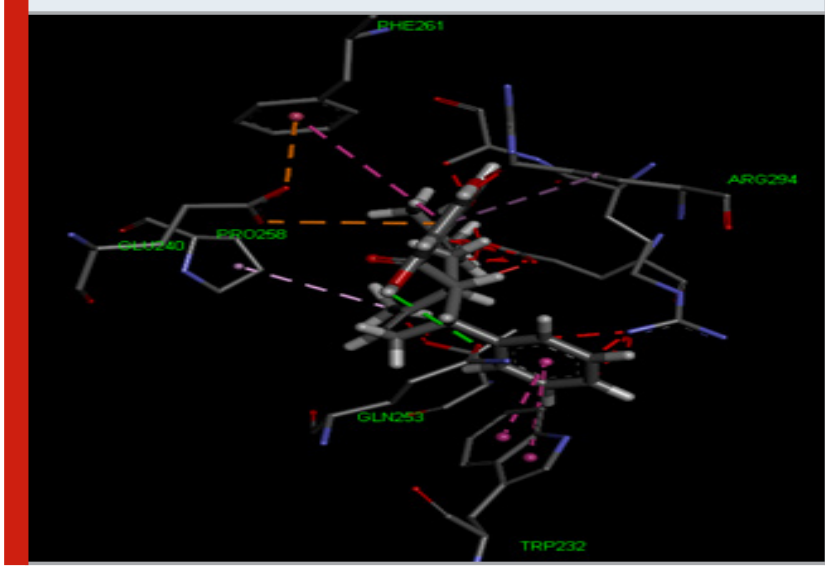

Figure 7: 2D Structure of docked model showing Amino Acid and Bond type

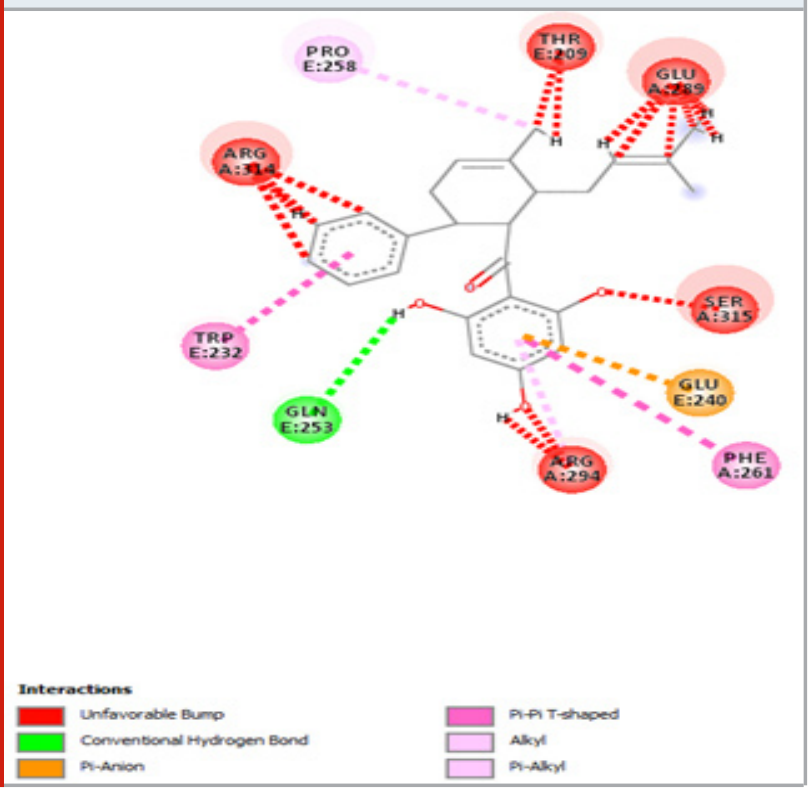

Autodock: Docking of 4-hydroxypanduratin A on DENV NS1 was performed using AutoDock. It is a software used for molecular modelling. Many scientists and researchers use this software to study the protein-ligand interaction. This software is freely accessible under GNU General Public License. It is the most favourable docking software used and cited by many researchers and scientists.

Drug Discovery Studio: Docked complex were then visualised using the BOVIA drug discovery studio .This software is useful for many scientists as they have to mind many parameters like they have to optimize biochemical potency and ADME and toxicity, then this software helps them to overcome this problem. It also helps in showing the protein-ligand interaction.

Data Collection: After performing the docking of 4-hydroxypanduratin A on DENV NS1, 10 docked conformations were recorded out of which the conformation which have the least global and Atomic Contact Energy 
(ACE) was selected. In Figure 5, 3D docked model with receptor is shown, for more clear understanding receptor is removed and the Docked complex with viral amino acids and 4-hydroxypanduratin A was recorded (Figure 6). To study the types of bond formed 2D structure of complex was constructed (Figure 7). Cloud model of Hydophobicity (Figure 8) and Ionizability(Figure 9) was also constructed to study the stability of docked complex.

Figure 8: Hydrophobicity of Docked Structure

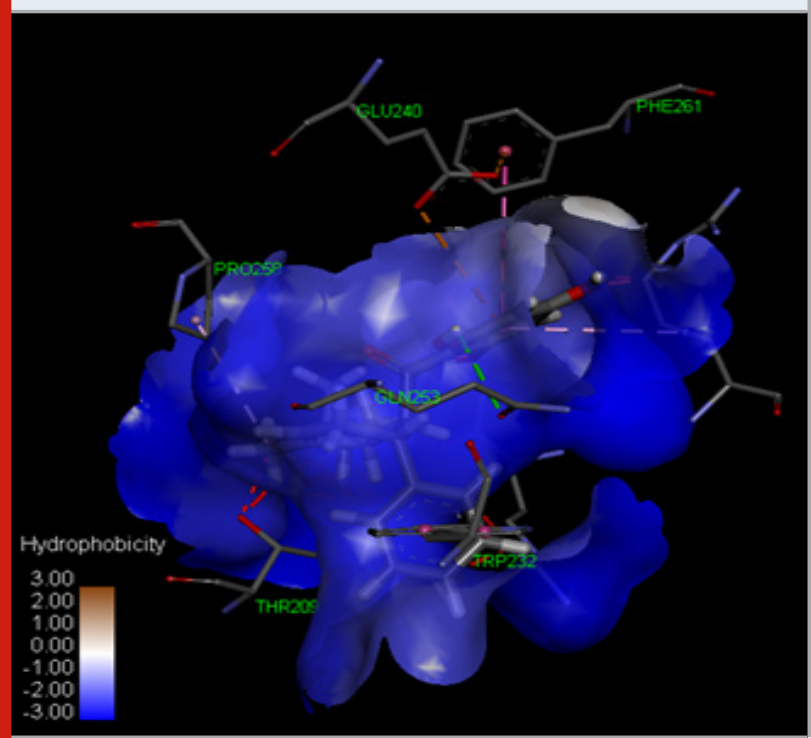

Data Analysis: It was found that the docked complex with the least Global energy and ACE were having 6 bonds and the distance was ranging from 3-5.5. In Figure 8, the blue clouds are showing the negative hydrophobicity while the white region if of neutral hydrophobicity. In Figure 9, Red region is for Acidic, White if for neutral and Blue is for the basic region between the Ligand and Protein. 1 hydrogen bond with GLN253, one electrostatic bond with GLU240 and 4 hydrophobic bonds with PHE261, TRP232, PRO258 and ARG294.

Table 1. Distance between bonds and types of bonds formed between Ligand: Protein

\begin{tabular}{|c|c|c|}
\hline Ligand : Protein & Distance & Bond Type \\
\hline UNL1 : GLN253 & 3.01096 & Hydrogen Bond \\
\hline UNL1 : GLU240 & 4.53965 & Electrostatic \\
\hline UNL1 : PHE261 & 5.53526 & Hydrophobic \\
\hline UNL1 : TRP232 & 4.09534 & Hydrophobic \\
\hline UNL1 : PRO258 & 4.4594 & Hydrophobic \\
\hline UNL1 : ARG294 & 4.89766 & Hydrophobic \\
\hline
\end{tabular}

\section{RESULTS AND DISCUSSION}

Atomic contact energy (ACE) energy is the energy of replacing the atom with an atom and Global Energy or Gibbs free energy is same as the binding energy of Ligand with protein. Less the ACE value and less distance between the

\section{Figure 9: Ionizability of Docked Structure}

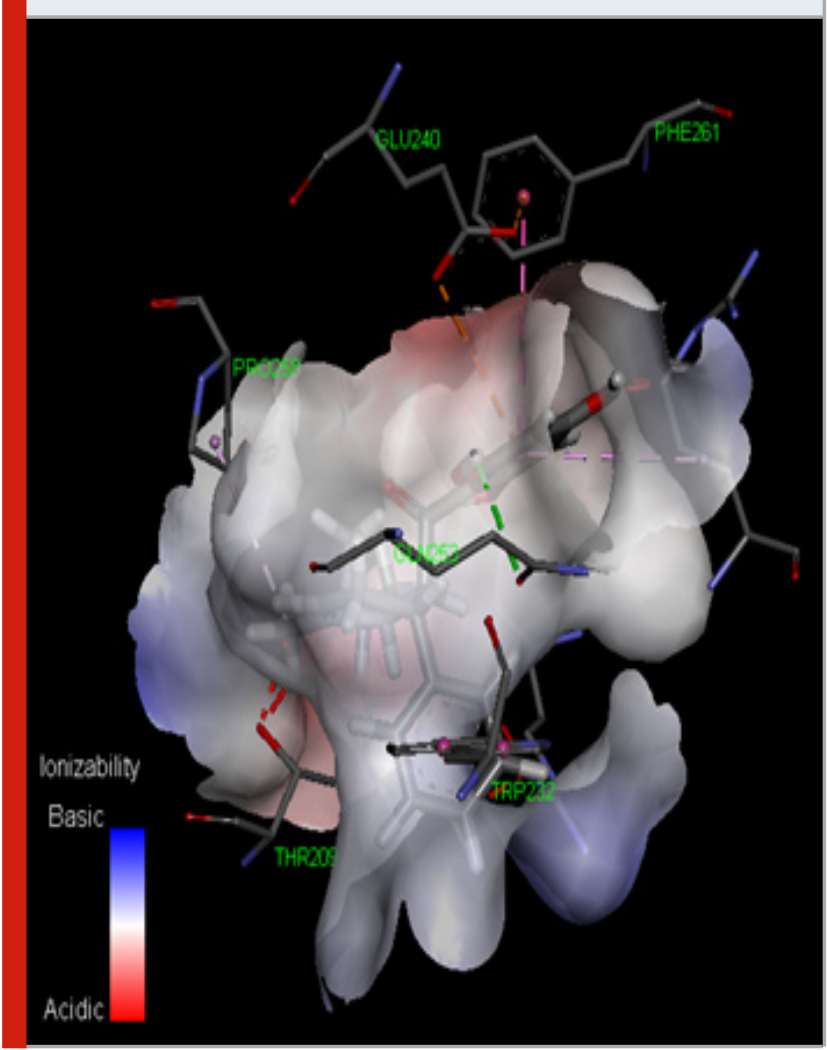

bonds depicts that the interaction is good. Three dimensional structures obtained after docking revealed that many bonds were forming. After the analysis it was found, that there were six bonds formed within the docked structure with a distance of ranging between 3 - 5.5. Hydrogen bond of ligand with (glutamine) GLN 253 with a distance of 3, Electrostatic bond of ligand with (glutamate) GLU240 with a distance of 4.5 and Hydrophobic bonds of ligand with (phenylalanine) PHE261, (tryptophan) TRP232, (proline) PRO258 and (arginine) ARG294 were formed with a distance ranging from 4 - 5.5. Obtained docked structure analysis also revealed that they have an Atomic contact energy (ACE) of $-93.99 \mathrm{kcal} / \mathrm{mol}$ and a Global Energy of $-30.53 \mathrm{kcal} / \mathrm{mol}$ was recorded.

\section{CONCLUSION}

Docking of a major component of Boesenbergia Rotunda which is 4-hydoxypanduratin A and Dengue Non-structural protein NS1 was performed and the study revealed that the phyto-compound 4-hydoxypanduratin A was forming hydrogen, hydrophobic and electrostatic bonds with DENV NS1. Results revealed that docked structures have less ACE and distance between the bonds formed is also varying from 3-5.5. These results conclude that 4-hydoxypanduratin A can be a therapeutic to target the DENV NS1 but further in-vitro research is needed. It can be a promising drug by targeting the DENV NS1.

\section{REFERENCES}

Amorim, J.H., dos Santos Alves, R.P., Boscardin, S.B. and de Souza Ferreira, L.C., 2014. The dengue virus non- 
structural 1 protein: risks and benefits. Virus research, 181, pp.53-60.

Frimayanti, N., Chee, C.F., Zain, S.M. and Rahman, N.A., 2011. Design of new competitive dengue Ns2b/ Ns3 protease inhibitors - a computational approach. International journal of molecular sciences, 12(2), pp.1089-1100.

Hunsperger, E., Kroeger, A., Margolis, H.S., Martnez, E., Nathan, M.B., Pelegrino, J.L., Simmons, C., Yoksan, S. and Peeling, R.W., 2010. Dengue: a continuing global threat. Nat Rev Microbiol, 8, p.S7S16.

Jing, L.J., Mohamed, M., Rahmat, A. and Bakar, M.F.A., 2010. Phytochemicals, antioxidant properties and anticancer investigations of the different parts of several gingers species (Boesenbergia rotunda, Boesenbergia pulchella var attenuata and Boesenbergia armeniaca). Journal of Medicinal Plants Research, 4(1), pp.027-032. Kato, F. and Hishiki, T., 2016. Dengue virus reporter replicon is a valuable tool for antiviral drug discovery and analysis of virus replication mechanisms. Viruses, 8(5), p.122.

Marliyana, S.D., Mujahidin, D., Syah, Y.M. and Rukayadi,
Y., 2017. Time-kill assay of 4-Hydroxypanduratin a isolated from Kaempferia Pandurata against foodborne pathogens. Molekul, 12(2), pp.166-173.

Muhamad, M., Tan, S.K., Khalid, N., Rahman, N.A. and Yusof, R., 2007. Inhibitory action of boesenbergia rotunda plant extracts towards dengue virus type-2 (den2) protease activity in vitro.

Seniya, C., Mishra, H., Yadav, A., Sagar, N., Chaturvedi, B., Uchadia, K. and Wadhwa, G., 2013. Antiviral potential of 4-hydroxypanduratin A, secondary metabolite of Fingerroot, Boesenbergia pandurata (Schult.), towards Japanese Encephalitis virus NS2B/NS3 protease. Bioinformation, 9(1), p.54.

Tuchinda, P., Reutrakul, V., Claeson, P., Pongprayoon, U., Sematong, T., Santisuk, T. and Taylor, W.C., 2002. Anti-inflammatory cyclohexenyl chalcone derivatives in Boesenbergia pandurata. Phytochemistry, 59(2), pp.169173.

Venkata Pavan, M., Karnan, B. and Latchoumi, T.P., 2021. PLA-Cu reinforced composite filament: Preparation and flexural property printed at different machining conditions. Advanced Composite Materials, https://doi. org/10.1080/09243046.2021, 1918608. 